\title{
Expert View
}

\section{Fostering Interdependence to Minimise Political Risks in a European-North African Renewable Electricity Supergrid}

\author{
Johan Lilliestam ${ }^{1,2, *}$ and Saskia Ellenbeck ${ }^{1}$ \\ ${ }^{1}$ Potsdam Institute for Climate Impact Research (PIK), \\ Telegrafenberg A31, 14473 Potsdam, Germany \\ ${ }^{2}$ International Institute for Applied Systems Analysis \\ (IIASA), Schlossplatz 1, 2361 Laxenburg, Austria
}

\begin{abstract}
The option of decarbonisation of the European power sector with the help of significant imports of renewable electricity from North Africa via a trans-continental electricity Supergrid is increasingly gaining attention. In this paper, we investigate the geopolitical risks to European energy security in such a future, and discuss cornerstones for possible policy strategies to reduce these risks. The strategies are rooted in the interdependence between exporter and importer. We come to the conclusion that fostering and deepening, as opposed to reducing, the dependence of both sides on each other may be a valuable and powerful way to reduce the geopolitical risks of renewable electricity trade between Europe and North Africa.
\end{abstract}

Keywords. energy security, Desertec, Supergrid, renewable electricity, interdependence.

\section{Introduction}

If Europe wants to stand a fair chance of reaching its longterm decarbonisation targets - at least $85 \%$ greenhouse gas emission reduction by 2050 - and shoulder its part of the global work to avoid dangerous climate change, the European power system has to be completely decarbonised in the coming four decades. On the electricity supply side, there are at least three principle ways of doing this: (1) expanding nuclear power, while solving its economic difficulties and accepting the environmental and safety risks involved with this technology; (2) developing carbon capture and storage technologies and accompanying infrastructures and applying these in a large scale to fossil fuel power generation; or (3) expanding renewable generation technologies and its accompanying infrastructures [1-5].

In this paper, we focus on the renewable option, which is an option that holds great promise: the technological and

* Corresponding author: Johan Lilliestam,

E-mail: johan@pik-potsdam.de, lilliest@iiasa.ac.at.

Received: February 27, 2012. Accepted: April 23, 2012. economic development of renewable generation technologies have made enormous progress in recent years, with onshore wind and biomass power approaching cost parity with conventional generation, and photovoltaic power (PV) at or below grid parity in most European countries. Other technologies, in particular offshore wind and concentrating solar power (CSP) are developing technologies, and are likely to undergo similar learning and cost reduction process over the coming decade [6]. Although the renewable generation technologies are still not fully mature, their prospects look bright and the large number of different technologies and concepts for expanding renewables offers a number of potentially viable ways to decarbonise the European power system.

\section{Background: the Supergrid}

In recent years, the idea of a Supergrid has emerged as one of the dominant paradigms for achieving very high levels of renewables. The Supergrid interlinks very large areas through a highly efficient high-voltage direct current (HVDC) power grid, which operates as an overlay grid on top of the HV alternating current grid. In many such scenarios, the Supergrid spans not only all of Europe, but also crosses the Mediterranean Sea. In these scenarios, Europe imports a significant share of its renewable power from North Africa. There are three main reasons why such an intercontinental Supergrid solution could be preferable to Europe compared to other renewables-based power system decarbonisation pathways:

- the solar power resources are much better in the deserts of North Africa than in Europe, which also offer large and very good potentials for wind power. Including these areas in the European power system could lead to significantly lower generation costs, also including transmission costs, than if Europe remains alone;

- the fluctuations of both intermittent renewables and to a lesser extent - demand are stochastically smoothed over very large areas, so a European-North African Supergrid would reduce the system costs for renewables by minimising the need for storage and by making the system more reliable and predictable;

- the land area and renewable resources within Europe may not be large enough to supply all of Europe's electricity needs in an economically viable fashion, while 
respecting ecological, acceptance and land-use competition, but the combined European-North African resources are large enough for almost any future demand [7-13].

Thus, the Supergrid proponents conclude that, from a technical and economical perspective, the risks associated with a Supergrid will be lower - i.e. cheaper and more reliable than a European-only renewables-based decarbonisation.

Despite this, an electricity future in which Europe depends on imports from North Africa for a substantial share of its electricity consumption raises fears of geopolitical risks and the "energy weapon" - of the exporters using the electricity trade and the European dependency to gain political leverage over Europe $[14,15]$. Such extortion events have happened in other energy markets: the 1973 oil crisis and the 2009 Russian-Ukrainian gas crisis are prominent examples. For a Supergrid system, this may be a challenge of a different quality than for other decarbonisation options: although Europe already today imports large shares of its primary energy, and nuclear and CCS futures would need to do so too, importing renewable electricity could introduce new geopolitical risks. In the following, we will dissect these "energy weapon" concerns, in order to identify possible strategies to increase the European geopolitical energy security in a possible Supergrid future.

\section{Strategies for Minimising Political Electricity Import Risks: Managing Interdependence}

There are two general ways to minimise risks: one can either minimise the impact or the probability of an event. For the importer, the potential impacts of an energy weapon event are the main concern, and measures to minimise them is a primary strategy to reduce risk. The exporter's tool in an energy weapon event is to inflict (or threaten to inflict) damage on the importer by cutting the energy deliveries. The impact - for example the damages inflicted on the importer - of such an event becomes a primary determinant for the attractiveness of the "energy weapon", and thus also for the probability of the event. This is valid even if the exporter only threatens to cut deliveries: if the threat is credible and strong, an actual disruption may not be necessary. Consequently, to be able to assess the risks of extortion events, one must understand their anatomy and especially what the impacts on the involved actors are.

Trading electricity - or energy, or any other commodity leads to interdependencies. Talking solely about import dependence is misleading: both the seller and the buyer have benefits of the trade, and thus both depend on it, to varying degrees. Focusing only on the importer's dependence removes the context of the issue, as import dependence is not a dangerous thing per se. Instead, the interesting question concerns the symmetry and quality of the trade: if one actor depends more on the trade than the other, then the less dependent actor can potentially use the trade as a source of bargaining power [16]. This logic works even stronger if the traded good, or the revenues from the trade, is a vital part of the economic activity of a country. Electricity is in this sense a more intense good than other energy carriers, for a number of reasons. First, all modern economic activity comes to a halt if the electricity supply is interrupted, which indicates a high importer vulnerability. In addition, supply and demand have to match at every time, or system instability or blackouts are the likely result. As electricity is grid-bound, substitution resources in the case of a disruption (such as reserve capacities) are restricted by the already existing infrastructure, which increases the interdependence between exporter and importer compared to other energy carriers, like oil. Further, whereas oil and gas can be stored in meaningful quantities, or left in the ground and sold at a later time, renewable electricity is a perishable good which is either sold and consumed momentarily, or it is lost. Hence, the impacts of a politically motivated electricity export disruption are more direct - they start at the instant the disruption begins - and affect both the importer and the exporter stronger than a similar event in the gas or oil supply system. Therefore, analogies to geopolitical risks in the gas and oil systems may be incorrect (see also [17]), as the systems are different.

In a recent paper [18], we investigate the interdependence and power symmetry in detail for the Desertec scenario, a Supergrid scenario foreseeing $100 \mathrm{GW}$, or about $17 \%$ of the European demand, renewable electricity imports from North Africa in 2050 [7, 13]. The conclusion of that article is that Europe is not particularly vulnerable to export cuts, for two main reasons.

First, Europe is likely to be able to restore system operations following all but the most extreme disruptions, as the magnitude of the imports from a given country is too low to exceed Europe's response capacities (mainly control and spare capacities, as well as demand reductions). In almost all cases, the blackouts are limited geographically and the system is likely to be reignited within hours; the impacts on the European economy are small and temporally limited.

The second reason is closely related, and leads us further towards possible strategies to minimise risks. Following an export cut, Europe first faces high blackout costs, but after a few hours the costs are minimal (caused by the slightly higher costs of reserve generation). The exporter, on the other hand, faces constant costs, originating in lost income, at a higher level than the European reserve generation costs, until the exports are resumed. As a consequence, the exporter has no leverage: Europe can simply wait the exporter out.

This result leads to a number of cornerstones for possible strategies to minimise the European geopolitical risks in a Supergrid future. The key to this lies in managing and fostering the interdependence between Europe and the exporters, including strategies affecting both the impacts of an 
extortion event, should it occur, and the probability that it happens by reducing the attractiveness for the exporters to wield the energy weapon. Three main priorities stand out:

First, diversifying the countries of origin reduces the potential leverage of each single supplier. Taking this argument seriously implies that production sites for renewable electricity should not be chosen exclusively based on costs and the quality of the solar or wind resources, but should also acknowledge the value of spreading the production across many countries. This means that it would be beneficial for Europe to seal electricity trade deals with as many countries as possible, and possibly limit each country's share, in order to avoid a dash for electricity from a single country with particularly good resources.

Second, increasing the response capacities on the European side further reduces the leverage of the exporters, as the impacts of a potential export cut are reduced. This does not necessarily, or at least not exclusively, mean that the physical control or spare capacities need to be increased compared to what is needed to protect the system against technical failures or natural events. Instead, it means increased demand-response capabilities and, in particular, the improved integration of the national power systems and markets, in order to spread the risks and enable a common European emergency response which is stronger than the response of single countries alone.

Third, increasing the exporters' dependence on the trade will reduce the attractiveness of a politically motivated export cut as it raises the stakes on the exporter side. This would in particular require the exporting countries themselves to invest in the power stations generating the renewable electricity and the export transmission lines. These assets have very high capital costs, and hence they depend on constant trade to be economical. If the exporters have made these sunk investments, cutting the exports will be all the more costly to them, and the incentives for a politically motivated disruption are lower. Similarly, emphasising local participation and benefits in the exporting countries is likely to benefit European energy security by further raising the stakes for the importer. Increasing local support and buy-in for electricity exports would require factors like local manufacturing of components in North Africa to be emphasised stronger, and the hiring of local people to work at the power stations to be actively encouraged. This, on the other hand, could make the Supergrid system less attractive to Europe, as it would pay for the electricity but a large share of the profits of the electricity trade, as well as a number of macro-economic advantages, would benefit North Africa instead of Europe.

This third point also highlights the hotly emphasised issue of ensuring that the exporters have sufficient generation capacity for their own needs before electricity is exported to Europe [19]: if, for whatever reason, the exporters have insufficient capacity, they have a very strong incentive to disrupt electricity exports in order to satisfy their own needs.
Hence, ensuring North African electricity sufficiency first is not only a moral issue of avoiding neo-colonial energy schemes, but it may prove to be vital also from a Eurocentric security perspective.

In addition to the issues addressed above, two further points affecting the probability that an extortion event happens will be discussed here. These points - which essentially also relate to interdependence in the broader sense are based on key conclusions from the studies of the European integration process and the growth of common European policies and organisations. Among the strongest conclusions in this body of research is that "institutions matter". The institutional integration in the EU is driven by a positive feedback loop of increasing economic integration and cross-border transactions, which activates supranational governance (e.g. dispute resolution and rule-making), which facilitates further expansion of economic integration and cross-border transaction, which creates a greater social demand for new supranational governance, and so on $[20,21]$. This institutional integration has changed the intra-European relations, and it has completely changed the European perception of international risks of depending on its neighbours. Applied to the discussion of political risks connected to the Supergrid vision, this allows for two important remarks.

First, good relations between Europe and North Africa will be of crucial importance. This is, of course, a trivial observation, but it is true and often forgotten in the discussion. Friendly relations both reduce the probability for hostile events to happen and increase the disincentives of an exporter to extort a partner: it is generally worse to break trust in a friendly than in a hostile relationship.

Second, the institutional setting greatly affects the possibilities to use the electricity trade as a political tool, and institutional integration between Europe and North Africa may thus prove to be a valuable way to manage the political risks, and change the perception of these. So far, much of the Supergrid discussion has viewed the exports as bulk transfer of dedicated export electricity, distinct from the general electricity supply framework [22]. This is a main source for the worries about political extortion risks: bulk point-to-point transfer is easy to understand, and lends itself very well to power considerations and analogies to pipeline gas import vulnerabilities [17]. If, however, the electricity is allowed to flow freely in a meshed system on an open European-North African market with common rules and institutions, the situation is completely different: it would be physically much more difficult (or impossible) to cut supply to a particular country, and the legal and practical possibilities of exporter governments to access energy trade as a forceful foreign policy instrument are reduced.

The value of these two points can be seen in the EU, where it is all but unthinkable that a government would seize control over its domestic electricity (or energy) com- 
panies (even if they are state-owned) in order to coax a neighbouring country into political concessions. This is not only due to the generally friendly relations within the $\mathrm{EU}$, but also due to the market structure and regulation, and the common institutions, which effectively make such action impossible and ineffective. The European laws and institutions outside the electricity and energy sectors add to this impossibility, and the economic integration raises the stakes of breaking existing law and aggressively punishing a neighbour country: a government nonetheless going ahead with (or threatening) such action would most likely face enormous reputational political (and possibly both direct and indirect economical) costs by being perceived an unreliable, aggressive partner. The consequence of the development of trust and common institutions is that European energy security cares little about in which EU country the electricity originates: today, electricity from a neighbouring European Union country is viewed as equally secure as domestically produced electricity.

Whether such integration is possible between Europe and North Africa, and to what extent, remains to be seen. From today's perspective, expectations of deeply friendly relations and institutional integration may seem optimistic or even naïve, but it is important to recognise the time component of a Supergrid decarbonisation process: the physical and institutional transformation would take place gradually over 40 years or more. It is certainly naïve to believe that this integration could happen over night, but at the same time it would be surprising if common institutions governing the Supergrid system would not evolve over time, if Europe and North Africa opt for this decarbonisation pathway.

\section{Conclusions}

The idea of a renewable Supergrid in which Europe imports renewable electricity from North Africa is frequently discussed as risky, due to the possibility of the exporters wielding the "energy weapon" and extorting Europe into political or economical concessions. However, recent analysis has shown that these risks are in fact small. In this article, a number of cornerstones for strategies to further reduce these political risks were discussed, by taking an interdependence perspective and acknowledging the context of a possible future electricity trade. These strategies come in three main shapes:

1. measures to minimise the impacts of an import disruption, especially by diversifying its supply countries and by integrating its domestic power systems, would reduce the European exposure to extortion risk;

2. actively emphasising the benefits for North Africa in order to increase the exporters' dependence on the exports would raise the stakes and reduce the attractiveness for the exporter to engage in extortion behaviour;
3. good relations would reduce the probability that a reason for the exporters to behave aggressively emerges, and deep institutional integration between Europe and North Africa, not necessarily limited to the electricity sector, would greatly reduce both the incentives and the possibilities (and hence the probability) for exporter governments to use electricity trade as a political tool.

Thus, instead of the intuitive answer to minimise dependence in order to increase energy security, targeted measures to deepen and foster dependence of both sides on each other may be a powerful overarching strategy to reduce $\mathrm{Eu}-$ ropean energy security risks in a renewable Supergrid electricity future.

\section{References}

[1] ECF. Roadmap 2050. Den Haag: European Climate Foundation 2010.

[2] EC. Energy roadmap 2050. COM(2011)885/2. Brussels: European Commission (EC) 2011.

[3] IPCC. IPCC fourth assessment report: Climate change 2007. Working Group I Report "The Physical Science Basis". Geneva: Intergovernmental Panel on Climate Change (IPCC) 2007.

[4] IPCC. IPCC fourth assessment report: Climate change 2007. Working Group II Report "Impacts, Adaptation and Vulnerability". Geneva: Intergovernmental Panel on Climate Change (IPCC) 2007.

[5] Metz B., Davidson O. R., Bosch P. R., Dave R., Meyer L. A., eds., IPCC fourth assessment report: Climate change 2007. Working Group III Report "Mitigation of Climate Change". Cambridge, Geneva: Cambridge University Press, Intergovernmental Panel on Climate Change (IPCC) 2007.

[6] IPCC. IPCC Special report on renewable energy sources and climate change mitigation. Cambridge: Cambridge University Press 2011.

[7] DLR. Trans-Mediterranean interconnection for concentrating solar power. Stuttgart: German Aerospace Centre (DLR) 2006.

[8] Battaglini A., Lilliestam J., Haas A., Patt A., Development of SuperSmart Grids for a more efficient utilisation of electricity from renewable sources. Journal of cleaner production. 17 (2009):911-8.

[9] Patt A., Komendantova N., Battaglini A., Lilliestam J., Regional integration to support full renewable power deployment for Europe by 2050. Environmental Politics. 20(5) (2011):727-42.

[10] Düren M., Clean power from deserts. Green - The international journal of sustainable energy conversion and storage. 1(3) (2011):263-75.

[11] MacKay D. J. C., Sustainable energy - without the hot air. Cambridge: UIT 2008.

[12] Czisch G., Szenarien zur zukünftigen Stromversorgung. Kostenoptimierte Variationen zur Versorgung Europas und seiner Nachbarn mit Strom aus erneuerbaren Energien [Dissertation]. Kassel: Universität Kassel; 2005. 
[13] Club of Rome. Clean power from deserts. The DESERTEC concept for energy, water and climate security. Hamburg: Club of Rome 2008.

[14] Pearce F., Sunshine superpower. New Scientist. 40-3 (2009).

[15] Irving S., The Desertec mirage. The validity of DII skepticism. 2010 [cited 2010.11.11]; Available from: http: //atlismta.org/online-journals/human-security /the-desertec-mirage/.

[16] Keohane R. O., Nye J. S., Power and interdependence. 3rd edition. New York: Longman 2001.

[17] Lacher W., Kumetat D., The security of energy infrastructure and supply in North Africa: Hydrocarbons and renewable energies in comparative perspective. Energy policy. 39 (2011):4466-78.

[18] Lilliestam J., Ellenbeck S., Energy security and renewable electricity trade: Will Desertec make Europe vulnerable to the "energy weapon"? Energy policy. 39 (2011):3380-91.

[19] Hickman L., Could the desert sun power the world? 2011 [cited 2012.01.26]; Available from: http: //www.guardian.co.uk/environment/2011/dec/11/ sahara-solar-panels-green-electricity.

[20] Sandholtz W., Stone Sweet A., Neo-functionalism and supranational governance. In: Jones E, Menon A, Weatherill S, eds. The Oxford handbook of the European Union. Oxford: Oxford university press in press.

[21] Puchala D., Institutionalism, intergovernmentalism, and European integration: A review article. Journal of common market studies. 37(2) (1999): 317-31.

[22] Trieb F., O’Sullivan M., Pregger T., Schillings C., Krewitt W., Characterisation of solar electricity import corridors from MENA to Europe. Stuttgart: German Aerospace Centre (DLR) 2009.

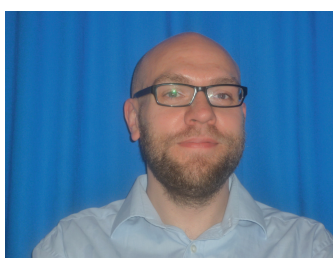

Johan Lilliestam works at the Potsdam Institute for Climate Impact Research (PIK) in Germany and at the International Institute for Applied Systems Analysis (IIASA) in Austria. Prior to this, he studied Environmental policy at the Freie Universität Berlin, Germany, and Environmental sciences at the University of Göteborg, Sweden. Johan Lilliestam is currently a PhD student in Environmental sciences and policy at the Central European University in Budapest, Hungary.

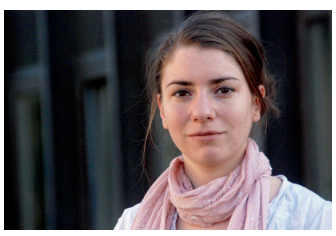

Saskia Ellenbeck studied Political sciences and Economics at the Universities of Aachen, Bordeaux and Potsdam and graduated in September 2009. During her studies, she worked in different research projects on environmental policy and international relations. In 2009-2010, she was a consultant at the Renewable Energy Policy Network (REN21) in Paris, France. Currently, she works at the parliament of North Rhine-Westphalia, Germany, as policy advisor for climate and energy issues. 